\title{
Early Pregnancy Glycemic Levels in Non-Diabetic Women and Pregnancy Outcome: A Retrospective Cross-Sectional Study
}

\author{
Naser Al-Husban (D) \\ Diala Walid Abu-Hassan ${ }^{2}$ \\ Ayman Qatawneh' \\ Zaid AISunna $\mathbb{D D}^{3}$ \\ Yasmine Alkhatib iD $^{3}$ \\ Seif Alnawaiseh ${ }^{3}$ \\ Moyasser Alkhatib ${ }^{3}$ \\ Maysa Yousef ${ }^{3}$ \\ 'Department of Obstetrics and \\ Gynecology, School of Medicine, The \\ University of Jordan, Amman, Jordan; \\ ${ }^{2}$ Department of Physiology and \\ Biochemistry, School of Medicine, The \\ University of Jordan, Amman, Jordan; \\ ${ }^{3}$ Obstetrics and Gynecology, Jordan \\ University Hospital, Amman, Jordan
}

Background: Maternal fasting blood sugar (FBS) variations within normal range and lower than that in diabetes mellitus (DM) may be associated with adverse feto-maternal outcomes. Objective: To find out if a rise of maternal FBS level above 80 but still below $120 \mathrm{mg} / \mathrm{dL}$ (group 2) has an influence on feto-maternal outcomes compared with a maternal FBS below $80 \mathrm{mg} / \mathrm{dL}$ (group 1).

Methods: Retrospective cross-sectional study. FBS was measured at the booking visit. Subjects whose FBS was measured before 20 weeks were categorized according to their FBS ( $>80 \mathrm{mg} / \mathrm{dL}$ or $\leq 80 \mathrm{mg} / \mathrm{dL}$ ) and correlation between FBS levels in the two groups with several parameters were tested.

Results: Group 1 (130 healthy pregnant women) and group 2 (88 healthy pregnant women) did not show a statistical difference in age or BMI. More statistically significant cases were diagnosed with GDM in group 2 than in group $1(39.8 \%$ vs $16.9 \%$, P value 0.000). More cases that needed pharmacological intervention in the form of metformin or insulin or both were seen in group 2 than in group 1 (p value 0.007 and 0.061 , respectively). More but not statistically significant polyhydramnios was seen more in group 2 than in group $1(9.1 \%$ vs $3.1 \%$, p value 0.056$)$. There was no statistically significant difference between the 2 groups in relation to all other fetomaternal outcome parameters that were studied.

Conclusion: Raised maternal fasting blood glucose level $(80-120 \mathrm{mg} / \mathrm{dL})$ in healthy primigravid women in early pregnancy was associated with significant diagnosis of gestational diabetes mellitus and need for pharmacological intervention. An association was found with polyhydramnios but this was not statistically significant. No influence was found on preterm birth, fetal weight, mode of delivery or APGAR score. More attention should be given to FBS levels early in pregnancy to reduce the risk for later complications.

Keywords: fasting, fetomaternal, glycemic, outcome, pregnancy
Correspondence: Naser Al-Husban Faculty of Medicine, Department of Obstetrics and Gynecology, The

University of Jordan, P. O Box 2194,

Amman, I194I, Jordan

Tel +962-77208608

Fax +96264643217

Email Husban48@yahoo.com

\section{Introduction}

Maternal hyperglycemia that is still less severe than that in diabetes mellitus (DM) may be associated with adverse feto-maternal outcomes. The results of HAPO Study Cooperative Research Group, et $\mathrm{al}^{1}$ indicated strong and continuous associations of maternal glucose levels below those diagnostic of diabetes with increased birth weight and cord blood C peptide levels. Recently, Farrar et $\mathrm{al}^{2}$ in a metaanalysis found that higher maternal sugar levels in mid and late pregnancy were related to increased perinatal complications. 
Fetal growth might be already abnormal in women diagnosed to have gestational diabetes mellitus (GDM), but this was difficult to interpret as maternal glucose levels before the diagnosis of GDM were unknown. ${ }^{3,4}$

Our aim was to find out if a rise of maternal fasting blood sugar (FBS) level above 80 but still below $120 \mathrm{mg} /$ $\mathrm{dL}$ had an influence on feto-maternal outcomes compared with a maternal FBS below $80 \mathrm{mg} / \mathrm{dL}$.

\section{Methods}

\section{Subject Selection and FBS Measurement}

This was a retrospective cross-sectional study conducted on the records of patients who were seen at the Gynecology and Obstetric clinics of Jordan University Hospital (JUH) in the period between January 2016 and December 2020. All primigravid women with FBS that were done in early pregnancy, ie, booking visit, before they completed 20 weeks of gestation (a total of 218 subjects) were included in this study. Sample size was calculated to be 158 subjects with a $90 \%$ power and 0.05 alpha. Based on patients' records, more than $80 \%$ of our patients had their booking visit FBS test before 14 weeks of gestation. The standard practice at JUH is to measure FBS at the booking visit and to perform oral glucose tolerance test (OGTT) at 26-28 weeks for all patients. In some exceptional cases with preexisting risk factor(s) such as high BMI, thyroid disease, previously born macrosomic newborns, previous history of shoulder impaction during delivery, OGTT is repeated at 34 weeks. Exclusion criteria were known diabetics, multiple pregnancies, thyroid dysfunction, patients taking steroids or any other medications for chronic illness (s) and those with missing data. We have divided the normal range of FBS levels into lower normal $(<80 \mathrm{mg} / \mathrm{dL})$ and upper normal $(80-120 \mathrm{mg} / \mathrm{dL})$ to determine whether an early measurement of normal but categorized (upper normal or lower normal) FBS levels would correlate with fetomaternal outcomes. Based on that, patients were divided into 2 groups; group 1 with a FBS less than $80 \mathrm{mg} / \mathrm{dl}$ and group 2 with a FBS 80 $120 \mathrm{mg} / \mathrm{dl}$. Pregnancy outcomes were then compared between the 2 groups. The $120 \mathrm{mg} / \mathrm{dl}$ was chosen as those with higher than $120 \mathrm{mg} / \mathrm{dl}$ fulfill the criteria of a manifest diabetes. ${ }^{5}$

Gestational age was confirmed by early ultra-sound (US) scan before 16 weeks of gestation. All FBS samples were measured at our biochemistry laboratory. FBS was measured using GLUC3 cassette from Roche, Germany.
The normal range for this cassette is $70-110 \mathrm{mg} / \mathrm{dL}$. From patients' records we collected data regarding patients' age, body mass index (BMI), FBS early in pregnancy, and any complication in the pregnancy or the pregnancy outcome including miscarriage (defined as pregnancy loss before completed 24 weeks gestation), preterm delivery (defined as spontaneous vaginal delivery before completed 37 weeks gestation), gestational age at delivery, polyhydramnios (defined as a deepest vertical pocket of $\geq 8 \mathrm{~cm}$; Society for Maternal-Fetal Medicine recommendations), congenital abnormality (minor or major), stillbirth, intrauterine fetal death (IUFD), pre-eclamptic toxemia (PET), neonatal death and mode of delivery. For those who underwent cesarean section (CS), the indications were also identified. Fetal outcome included birth weight; APGAR score at 1 minute and APGAR score at 5 minutes. The APGAR score was determined by the neonatologists who routinely attend deliveries at our hospital.

We also identified those who were diagnosed to have gestational diabetes mellitus (GDM) with any intervention (metformin or insulin and their dosages). Diagnosis of GDM was based on a standard 75 OGTT at 26-28 weeks gestation. A normal FBS level is lower than $95 \mathrm{mg} / \mathrm{dL}$, one hour lower than $180 \mathrm{mg} / \mathrm{dL}$, two hours lower than $155 \mathrm{mg} / \mathrm{dL}$, three hours after drinking the glucose solution, and a normal blood glucose level is lower than $140 \mathrm{mg} / \mathrm{dL}$. Data concerning the primary outcomes such as the diagnosis of GDM and preterm birth were collected from patients' files (both paper and electronic); antenatal clinic appointments, admission notes and delivery records. The study flow is shown in Figure 1.

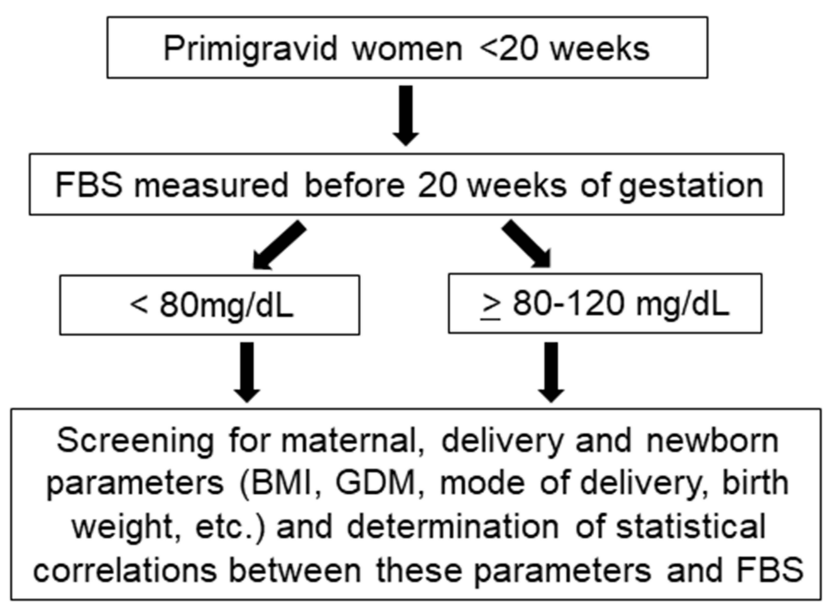

Figure I Study flow chart.

Abbreviations: BMI, body mass index, FBS, fetal bovine serum, GDM, gestational diabetes mellitus. 


\section{Statistical Analysis}

Statistical analysis was performed using Statistical Package for Social Sciences (SPSS) version 16 (Chicago, Illinois, USA). Quantitative results were shown as mean \pm standard deviation (SD). Qualitative results were shown as counts and percentages (\%). The significance of associations between fasting blood sugar category (above 80 , or lower than or equal to 80 ) and quantitative variables was tested by analysis of variance (ANOVA). The association between fasting blood sugar category (above 80 , or lower than or equal to 80) and categorical variables was tested by Chi-square $\chi^{2}$ test. Results were considered statistically significant when $P$ value is less than 0.05 . The study sample size was powered for the primary outcomes; GDM and preterm birth.

\section{Ethical Approval/Patient Consent}

The study obtained approval of the institutional review board (IRB) at Jordan University Hospital number; 129/ 2019 , dated 19/03/2019. It was also registered with clinicaltrials.gov with a unique identifier number; NCT04756102. The consent form was waived as the study was a retrospective review of the medical files and anonymity was maintained all the way during data collection and manuscript writing. This study was conducted in accordance with the declaration of Helsinki.

\section{Results}

There were 130 women in group 1 and 88 in group 2. No statistical difference between the two groups regarding maternal age and BMI was detected (Table 1). There were more statistically significant cases diagnosed with GDM in group 2 than in group $1(39.8 \%$ vs $16.9 \%$, $\mathrm{P}$ value 0.000 ). Consequently, there were more cases that needed pharmacological intervention in the form of metformin or insulin or both in group 2 than in group $1(\mathrm{p}$ value 0.007 and 0.061 , respectively) (Table 1). Even if
FBS $\leq 80 \mathrm{mg} / \mathrm{dL}$, GDM was not excluded but its risk was reduced significantly (Table 1). OGTT test was performed for all subjects as a routine practice at JUH and it was used to diagnose GDM later even in subjects with FBS $<80 \mathrm{mg} /$ dL before 20 weeks. A Receiver operating characteristic (ROC) curve was drawn on SPSS to find the cut-off value of FBS that is associated with GDM and found to be $75.5 \mathrm{mg} / \mathrm{dL}$ (Figure 2).

Polyhydramnios was seen more in group 2 than in group 1 but this difference did not reach a statistical significance $(9.1 \%$ vs $3.1 \%$, p value 0.056$)$ (Table 2$)$. There was no statistically significant difference between the 2 groups in relation to all other fetomaternal outcome that were studied (Table 2). Only 11 women in group 2 $(12.5 \%)$ had FBS more than $95 \mathrm{mg} / \mathrm{dl}$.

\section{Discussion}

Our findings showed a significant association between FBS level between 80 and $120 \mathrm{mg} / \mathrm{dl}$ in pregnant women and the development of GDM (group 2, 39.8\% vs group 1, 16.9\%, $\mathrm{P}$ value 0.000 ) with a statistically significant need for pharmacological intervention, either metformin, insulin or both, in group 2 than in group 1 (p value 0.007 and 0.061 , respectively). Twenty-two subjects in group 1 developed GDM later in pregnancy and they were diagnosed in reference to the results of OGTT test that is routinely performed for all patients at 2628 weeks of gestation. Other factors that might have contributed to this including family history and/or BMI, which was elevated on average in this group (Table 1). The elevation in FBS in group 2 increased polyhydramnios but not significantly (group 2, 9.1\% vs group 1, 3.1\%, p value 0.056 ). In our study, the difference in BMI between the two groups was not statistically significant ( $\mathrm{P}$ value 0.504 ). This excluded the influence of weight on the difference in the risk of glucose intolerance and development of GDM between group 1 and 2. However, the mean BMI was $28.9 \pm 6.4$ and $29.4 \pm 5.2$ in group 1 and 2,

Table I Clinical Characteristics of Subjects Based on Their Fasting Blood Sugar Level

\begin{tabular}{|l|l|l|l|l|}
\hline Clinical Characteristics & & Group I N=130 & Group 2 N=88 & $P$ \\
\hline FBS & & $73.0 \pm 5.0$ & $88.4 \pm 8.5$ & 0.000 \\
Age & & $31.5 \pm 4.7$ & $31.9 \pm 4.9$ & 0.497 \\
BMI & & $28.9 \pm 6.4$ & $29.4 \pm 5.2$ & 0.504 \\
Diagnosed with GDM & $22(16.9)$ & $35(39.8)$ & 0.000 \\
Intervention & Metformin & $20(15.4)$ & $27(30.7)$ & 0.007 \\
& Insulin & $6(4.6)$ & $10(11.4)$ & 0.061 \\
\hline
\end{tabular}

Notes: Qualitative data was represented as counts and (percentages). Quantitative data was represented as mean + standard deviation. $\mathrm{P}$ value less than 0.05 was considered significant.

Abbreviations: BMI, body mass index; FBS, fasting blood sugar; GDM, gestational diabetes mellitus. 


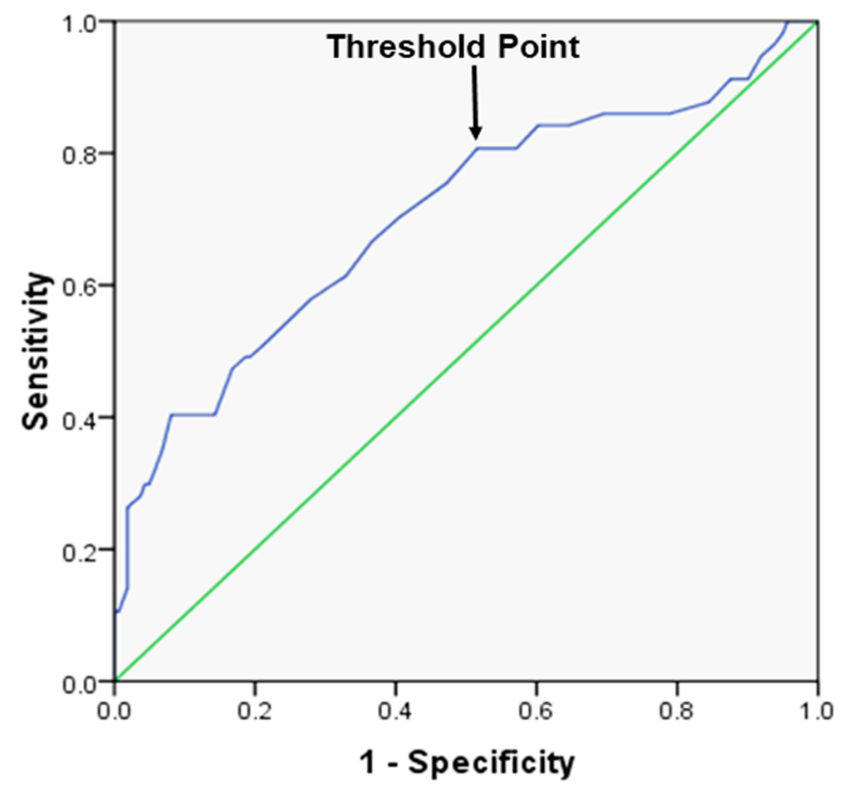

Figure 2 Receiver operating characteristic (ROC) curve. Note: Threshold point is marked with an arrow and is equivalent to $75.5 \mathrm{mg} / \mathrm{dL}$ fasting blood sugar level.

respectively. Studies from other research groups showed that obese women were 3 to 5.5 times more likely to develop GDM than normal weight women. ${ }^{6}$ Both groups were not known to have thyroid disease. Thyroid disorders and diabetes were known to be associated and the prevalence of specific thyroid disorders in diabetic subjects was found to be two times higher. $^{7,8}$ Our patients were not receiving medications like steroids that could cause elevated blood glucose levels. ${ }^{9}$ Both groups also had no previous miscarriages. We found more cases of polyhydramnios in the second group but this finding did not reach a statistical significance. There was no significant difference in preterm birth or gestational age at delivery. In a retrospective cohort study ${ }^{10}$ comparing fetomaternal outcomes in gestational diabetes and lesser glucose intolerance degrees, an increased risk of pre-eclampsia and macrosomia was found in both the GDM and impaired fasting glucose. They also found an increased risk of polyhydramnios similar to our finding. In our study, there was no significant difference in development of PET or macrosomia. Mild gestational diabetes was associated with perinatal morbidity through an increased GDM diagnosis. ${ }^{11}$ We found a statistically significant increase in the diagnosis of GDM and the need for pharmacological intervention in group two ( $\mathrm{P}$ value 0.00 ). This indicated the need to scrutinize those pregnant patients with impaired fasting glucose. As it was done in our study within the context of booking tests, FBS could serve as an easy to do and affordable potential laboratory test in early pregnancy. Yoffe et $\mathrm{al}^{12}$ suggested that circulating microRNAs were potential biomarkers and could be a novel early non-invasive diagnostic tool for GDM. Correa et $\mathrm{al}^{13}$ used fasting blood glucose in addition to other first trimester maternal biomarkers for early prediction of GDM. Other investigators also used different biomarkers for early diagnosis of GDM. ${ }^{14-17}$

There were no statistically significant differences between the 2 groups in relation to congenital anomalies, PET, IUFD, stillbirth, birth weight and cesarean delivery. Stogianni et $\mathrm{al}^{18}$ in a similar population size to our study found that GDM did not increase risk of cesarean section, preterm delivery and large for gestational age (LGA) compared with pre-gestational diabetes patients.

In a large study, GDM that necessitated insulin therapy was found by Billionnet et $\mathrm{al}^{19}$ to be associated with a moderately increased risk of adverse perinatal outcomes. This influence was not seen in our study since the number of women in our study who were diagnosed with GDM and required insulin treatment in group 2 was only 10. Around one-third of our patients who were diagnosed with GDM in group 2 were given metformin. This might have contributed to the absence of any case of PET in this group. Metformin might play a role in the prevention of preeclampsia through reducing the production of antiangiogenic factors and the improvement of endothelial dysfunction. ${ }^{20}$

There were no cases of fetal macrosomia in our study as even cases that subsequently developed GDM were treated and controlled. Kc et $\mathrm{al}^{21}$ found that fetal macrosomia was a common adverse sequel of unrecognized and untreated GDM. Hartling et $\mathrm{al}^{22}$ in their review found that treatment of GDM resulted in less preeclampsia and macrosomia. There was no significant difference in cesarean delivery rate among the 2 groups in our study. Nakabuye et $\mathrm{al}^{23}$ in their prospective cohort found that macrosomia was the only obstetric outcome that was significantly associated with hyperglycemia with no difference in neonatal outcome. The HAPO Study Cooperative Research Group found strong, continuous associations of maternal glucose levels below those diagnostic of diabetes with increased birth weight and increased cord-blood serum C-peptide levels. ${ }^{1}$ Unfortunately, they did not study the effect on APGAR scores. APGAR scores were not significantly different in our patients. In GDM patients who were untreated, Maryns et $\mathrm{al}^{24}$ found that there were more cases of pre-eclampsia and more neonatal admissions than in the treated group. In addition, pregnancy duration was shorter and APGAR score at five minutes was significantly lower in the untreated than the treated group. 
Table 2 Pregnancy, Delivery and New-Born Data of Subjects Based on Their Fasting Blood Sugar Level

\begin{tabular}{|c|c|c|c|c|}
\hline Delivery and New-Born Data & & Group I $N=\mid 30$ & Group $2 \mathrm{~N}=88$ & $P$ \\
\hline History of miscarriage & & $0(0)$ & $0(0)$ & - \\
\hline Preterm delivery & & $19(14.6)$ & $17(19.3)$ & 0.361 \\
\hline Mode of delivery (NVD:CS) & & $72: 58(55.4: 44.6)$ & $43: 45(48.9: 5 I .1)$ & 0.346 \\
\hline CS indications (elective: urgent) & $68: 33(67.3: 32.7)$ & $41: 17(70.7: 29.3)$ & $27: 16(62.8: 37.2)$ & 0.408 \\
\hline Elective & $\begin{array}{l}\text { Maternal request } \\
\text { Breech } \\
\text { LGA } \\
\text { Previa } \\
\text { Others }\end{array}$ & $\begin{array}{l}5 \\
1 \\
1 \\
0 \\
33\end{array}$ & $\begin{array}{l}4 \\
2 \\
1 \\
0 \\
21\end{array}$ & \\
\hline Urgent & $\begin{array}{l}\text { FD } \\
\text { FTP } \\
\text { APH } \\
\text { PET } \\
\text { Abruption } \\
\text { Cord collapse } \\
\text { Failed vacuum or forceps } \\
\text { Others }\end{array}$ & $\begin{array}{l}5 \\
0 \\
1 \\
2 \\
0 \\
0 \\
0 \\
9\end{array}$ & $\begin{array}{l}3 \\
3 \\
0 \\
1 \\
0 \\
0 \\
0 \\
8\end{array}$ & \\
\hline GA at delivery & & $38.1 \pm 1.7$ & $37.8 \pm 1.5$ & 0.332 \\
\hline Polyhydramnios & & $4(3.1)$ & $8(9.1)$ & 0.056 \\
\hline PET & & $\mathrm{I}(0.8)$ & $0(0)$ & 0.412 \\
\hline Birth weight & & $3.0 \pm 0.7$ & $3.0 \pm 0.4$ & 0.924 \\
\hline Twins & & $5(3.8)$ & $2(2.3)$ & 0.520 \\
\hline Stillbirth & & $0(0)$ & $0(0)$ & - \\
\hline Congenital abnormality & & $0(0)$ & $2(2.3)$ & 0.084 \\
\hline Neonatal death & & $\mathrm{I}(0.8)$ & $0(0)$ & 0.412 \\
\hline IUFD & & $\mathrm{I}(0.8)$ & $0(0)$ & 0.412 \\
\hline APGAR score at I minute & & $7.90 \pm 0.8$ & $7.94 \pm 0.4$ & 0.407 \\
\hline APGAR score at 5 minute & & $8.92 \pm 0.6$ & $8.99 \pm 0.2$ & 0.348 \\
\hline
\end{tabular}

Notes: Qualitative data was represented as counts and (percentages). Quantitative data was represented as mean + standard deviation. $\mathrm{P}$ value less than 0.05 was considered significant.

Abbreviations: APGAR, appearance, pulse, grimace, activity, and respiration; APH, Antepartum haemorrhage; CS, Caesarean section; FBS, fasting blood sugar; FD, fetal distress; FTP, failure to progress; GA, gestational age; IUFD, intrauterine fetal death; LGA, large for gestational age; NVD, normal vaginal delivery; PET; pre-eclamptic toxaemia.

Our study findings could be used to encourage followup of those with hyperglycemia and those who were diagnosed with GDM. Dalfrà et $\mathrm{al}^{25}$ concluded that postpartum follow-up and adherence factors of those with GDM were important. Moreover, ongoing glucose screening was found to be indicated for all women with GDM. ${ }^{26}$

The strengths of this study were an adequate sample size and controlling for multiple confounding factors such as age, multiple deliveries and BMI. The main aim of this study was to find out whether normal FBS levels at an early time during pregnancy might act as an early alarm that implicated certain risks and effects on fetomaternal outcome. Although our sample was adequate, repetition of this study in multi-racial populations with a larger sample size may show a clearer influence on fetomaternal outcome. Retrospective nature of our study was a limitation. We recommend prospectively repeating such a study. 


\section{Conclusions}

Elevated early pregnancy maternal fasting blood glucose levels (before 20 weeks of gestation) to $80 \mathrm{mg} / \mathrm{dL}-120 \mathrm{mg}$ / $\mathrm{dL}$ are associated with a higher risk for GDM development when compared to values $<80 \mathrm{mg} / \mathrm{dL}$. However, a high proportion of primigravidas with FBS $<80 \mathrm{mg} / \mathrm{dL}$ before 20 weeks of gestation are overweight, thereby, the risk for GDM cannot be excluded in these subjects and the FBS test, therefore, cannot replace the 26-28 weeks OGTT in this population. When considering other parameters, an association of FBS level with polyhydramnios was found, though insignificant. No influence was detected on preterm birth, fetal weight, mode of delivery or APGAR score. Clinicians should give more attention to FBS levels early in pregnancy as a preventive step to decrease the risk for later complications.

\section{Ethical Approval /Patient Consent}

Ethics approval was obtained by the institutional review board (IRB) at Jordan University hospital. Patient consent was waived as the study was a retrospective review of the medical files and anonymity was maintained all the way during data collection and manuscript writing. This study was conducted in accordance with the declaration of Helsinki.

\section{Funding}

There is no funding to report.

\section{Disclosure}

All authors declare no conflicts of interest in this work.

\section{References}

1. Metzger BE, Lowe LP, Dyer AR, et al.; HAPO Study Cooperative Research Group. Hyperglycemia and adverse pregnancy outcomes. $N$ Engl J Med. 2008;358(19):1991-2002. PMID: 18463375. doi:10.1056/NEJMoa0707943

2. Farrar D, Simmonds M, Bryant M, et al. Review hyperglycaemia and risk of adverse perinatal outcomes: systematic review and meta-analysis. BMJ. 2016;13(354):i4694. doi:10.1136/bmj.i4694

3. Sovio U, Murphy HR, Smith GC. Accelerated fetal growth prior to diagnosis of gestational diabetes mellitus: a prospective cohort study of nulliparous women. Diabetes Care. 2016;39(6):982-987. doi: $10.2337 / \mathrm{dc} 16-0160$

4. Sletner L, Jenum AK, Yajnik CS, et al. Fetal growth trajectories in pregnancies of European and South Asian mothers with and without gestational diabetes, a population-based cohort study. PLoS One. 2017;12(3):e0172946. PMID: 28253366; PMCID: PMC5333847. doi:10.1371/journal.pone.0172946

5. Kautzky-Willer A, Harreiter J, Winhofer-Stöck1 Y, et al. Gestationsdiabetes (GDM) (Update 2019) [Gestational diabetes mellitus (Update 2019)]. Wien Klin Wochenschr. 2019. 131(Suppl 1):91-102. doi:10.1007/s00508-018-1419-8. German. PMID: 30980150 .
6. Kim SS, Zhu Y, Grantz KL, et al. Obstetric and neonatal risks among obese women without chronic disease. Obstet Gynecol. 2016;128 (1):104-112. PMID: 27275800. doi:10.1097/AOG.000000 0000001465

7. Tromba V, Silvestri F, Costantino F. Type 1 diabetes mellitus and thyroid diseases: relationship between glycometabolism and thyroid function. Minerva Endocrinol. 2020;45(1):70-71. PMID: 31286754. doi:10.23736/S0391-1977.19.02996-1

8. Reismann P, Somogyi A. Cukorbetegség és pajzsmirigybetegségek [Diabetes and thyroid disorders]. Orv Hetil. 2011. 152(13):516-519. doi:10.1556/OH.2011.29056. Hungarian. PMID: 21398213.

9. Patel DA, Kristensen PL, Pedersen-Bjergaard U, Schultz HH. [Glucocorticoid-induced diabetes and risk factors during high-dose therapy]. Ugeskr Laeger. 2018;180(18):V06170454. Danish. PMID: 29720341

10. Nordin NM, Wei JW, Naing NN, Symonds EM. Comparison of maternal-fetal outcomes in gestational diabetes and lesser degrees of glucose intolerance. J Obstet Gynaecol Res. 2006;32(1):107-114. PMID: 16445535. doi:10.1111/j.1447-0756.2006.00360.x

11. Cundy T, Ackermann E, Ryan EA. Gestational diabetes: new criteria may triple the prevalence but effect on outcomes is unclear. $B M J$. 2014;348(3):g1567. PMID: 24618099. doi:10.1136/bmj.g1567

12. Yoffe L, Polsky A, Gilam A, et al. Early diagnosis of gestational diabetes mellitus using circulating microRNAs. Eur J Endocrinol. 2019;181(5):565-577. PMID: 31539877. doi:10.1530/EJE-19-0206

13. Correa PJ, Venegas P, Palmeiro Y, et al. First trimester prediction of gestational diabetes mellitus using plasma biomarkers: a case-control study. J Perinat Med. 2019;47(2):161-168. PMID: 30205647. doi:10.1515/jpm-2018-0120

14. Hocaoglu M, Demirer S, Senturk H, Turgut A, Komurcu-Bayrak E. Differential expression of candidate circulating microRNAs in maternal blood leukocytes of the patients with preeclampsia and gestational diabetes mellitus. Pregnancy Hypertens. 2019;17:5-11. PMID: 31487656. doi:10.1016/j.preghy.2019.04.004.

15. Nevalainen J, Sairanen M, Appelblom H, Gissler M, Timonen S, Ryynänen M. First-trimester maternal serum amino acids and acylcarnitines are significant predictors of gestational diabetes. Rev Diabet Stud. 2016;13(4):236-245. PMID: 28278310; PMCID: PMC5734224. doi:10.1900/RDS.2016.13.236

16. Lorenzo-Almorós A, Hang T, Peiró C, et al. Predictive and diagnostic biomarkers for gestational diabetes and its associated metabolic and cardiovascular diseases. Cardiovasc Diabetol. 2019;18(1):140. PMID: 31666083; PMCID: PMC6820966. doi:10.1186/s12933-0190935-9

17. Bao W, Baecker A, Song Y, Kiely M, Liu S, Zhang C. Adipokine levels during the first or early second trimester of pregnancy and subsequent risk of gestational diabetes mellitus: a systematic review. Metabolism. 2015;64(6):756-764. PMID: 25749468; PMCID: PMC4625979. doi:10.1016/j.metabol.2015.01.013

18. Stogianni A, Lendahls L, Landin-Olsson M, Thunander M. Obstetric and perinatal outcomes in pregnancies complicated by diabetes, and control pregnancies, in Kronoberg, Sweden. BMC Pregnancy Childbirth. 2019;19(1):159. PMID: 31064335; PMCID: PMC6505274. doi:10.1186/s12884-019-2269-8

19. Billionnet C, Mitanchez D, Weill A, et al. Gestational diabetes and adverse perinatal outcomes from 716,152 births in France in 2012. Diabetologia. 2017;60(4):636-644. PMID: 28197657; PMCID: PMC6518373. doi:10.1007/s00125-017-4206-6

20. Romero R, Erez O, Hüttemann M, et al. Metformin, the aspirin of the 21st century: its role in gestational diabetes mellitus, prevention of preeclampsia and cancer, and the promotion of longevity. Am $J$ Obstet Gynecol. 2017;217(3):282-302. PMID: 28619690; PMCID: PMC6084482. doi:10.1016/j.ajog.2017.06.003

21. Kc K, Shakya S, Zhang H. Gestational diabetes mellitus and macrosomia: a literature review. Ann Nutr Metab. 2015;66(Suppl 2):14-20. PMID: 26045324. doi:10.1159/000371628 
22. Hartling L, Dryden DM, Guthrie A, et al. Screening and diagnosing gestational diabetes mellitus. Evid Rep Technol Assess. 2012; (210):1-327. PMID: 24423035; PMCID: PMC4781607.

23. Nakabuye B, Bahendeka S, Byaruhanga R. Prevalence of hyperglycaemia first detected during pregnancy and subsequent obstetric outcomes at St. Francis Hospital Nsambya. BMC Res Notes. 2017;10(1):174. PMID: 28464913; PMCID: PMC5414152. doi:10.1186/s13104-017-2493-0

24. Maryns AS, Dehaene I, Page G. Maternal and neonatal outcomes in a treated versus non- treated cohort of women with gestational diabetes mellitus according to the HAPO 5 and 4 criteria. Facts Views Vis Obgyn. 2017;9(3):133-140. PMID: 29479398; PMCID PMC5819321.
25. Dalfrà MG, Burlina S, Del Vescovo GG, Anti F, Lapolla A Adherence to a follow-up program after gestational diabetes. Acta Diabetol. 2020;57(12):1473-1480. PMID: 32740702. doi:10.1007/ s00592-020-01564-y

26. Ingram ER, Robertson IK, Ogden KJ, Dennis AE, Campbell JE, Corbould AM. Utility of antenatal clinical factors for prediction of postpartum outcomes in women with gestational diabetes mellitus (GDM). Aust N Z J Obstet Gynaecol. 2017;57(3):272-279. PMID: 27549600. doi:10.1111/ajo.12514

\section{Publish your work in this journal}

The International Journal of General Medicine is an international, peer-reviewed open-access journal that focuses on general and internal medicine, pathogenesis, epidemiology, diagnosis, monitoring and treatment protocols. The journal is characterized by the rapid reporting of reviews, original research and clinical studies across all disease areas. The manuscript management system is completely online and includes a very quick and fair peer-review system, which is all easy to use. Visit http://www.dovepress.com/ testimonials.php to read real quotes from published authors.

Submit your manuscript here: https://www.dovepress.com/international-journal-of-general-medicine-journal 